\title{
Improving Autistic Children's Social Skills Using Virtual Reality
}

\author{
Omaima Bamasak, Roa'a Braik, Hadeel Al-Tayari, Shatha Al-Harbi, \\ Ghadeer Al-Semairi, and Malak Abu-Hnaidi \\ Computer Science Department, College of Computing and Information Technology, \\ King AbdulAziz University, Jeddah, Saudi Arabia \\ obamasek@kau.edu.sa, \\ \{computergirl_4, hadeel.mahamed, sha_magh, gadooorah\} @yahoo.com \\ mabuhenidi@gmail.com
}

\begin{abstract}
This project presents an approach to improve autistic children's social and interactive behavior through involving them in an interactive virtual reality environment. The targeted group is in the age of 5 to 16 years. The environment to be simulated is a typical house. The autistic child will have the chance to move from one room to another and to engage in a series of activities related to each of these rooms. After each activity in each room, games will be presented to test the child's understanding and perception of the aforementioned activities. Using our developed software, the autistic children gaining improvement in their communication skills such as following commands, identifying vocabulary, linking the words to their meaning and eye contacts. They will also witness an improvement in learning the religious routines, daily habits, awareness of danger and awareness of surrounding environment.
\end{abstract}

Keywords: Autism, Autistic children, virtual reality, social skill, behavior, simulate, software.

\section{Introduction}

Children are invaluable assets, they are the men and women of the future who will lead the next generation. Autistic children are part of the community and of our families. "Education for All, Education for Excellence, Excellence for All", all mankind deserve this regardless of any obstacles that may impede their learning process, whether it is physical or mental, to give them the opportunities to shine and lead. This can be done by giving them the same attention and support that are given to the normal children to enhance their learning and understanding abilities.

Autism is a severe developmental disability that generally begins at birth or within the first three years of life. It is the result of a neurological disorder that changes the way the brain functions -- causing delays or problems in many different skills from infancy to adulthood. For example, both children and adults with autism usually exhibit difficulties in social interaction as well as in verbal and non-verbal communication. They also tend to be interested in odd, repetitive, or restricted activities. While 
the majority of autistic children look completely normal, they differ from other children by engaging in perplexing and distressing behaviors [1].

Statistics about autism have been particularly rare in the Middle East. One rough estimate is that the prevalence of autism in Saudi Arabia is 18 per 10,000, which is slightly higher than the 13 per 10,000 reported in the developed countries. Also, males are four times more likely to have ASD than females [2] .

Several methods have been developed over the past forty years to educate children with autism, including Applied Behavior Analysis, the TEACCH program, and sign training. These methods have proven successful to varying degrees, but come at a high cost, in terms of both time and money, due to their intensive nature. In addition, these successes are often dependent on prior student ability, working better for some subpopulation

Children with autism seem to learn best when the instructional material is presented in visual form. In this case it might be worthwhile to try different computerbased educational programs. For children, using a computer for learning is fun and attractive. The majority of educational programs are highly visual. Many of the games available involve storylines, plots, and realistic human behaviors.

Therefore, we have chosen the virtual reality concept to simulate a real home for the rehabilitation of autistic children in an attempt to improve their social and behavioral side. This choice was made because the main benefit identified for this type of disability is that the autistic children can engage in a range of activities in a simulator relatively free from the limitations imposed by their disability, and they can do so safely. Evidence that the knowledge and skills acquired by disabled individuals in simulated environments can transfer to the real world is presented. Hence, the focus of the project is not to diagnose the case, propose a treatment and then monitor the progress when applying the treatment. The remaining of the paper is organized as follows: Section 2 presents and analyzes related work in the filed, Section 3 outlined the requirements specification, Section 4 explains software architecture, Section 5 describes the implementation process, Section 6 presents the software testing results on sample of real users, and finally Section 7 concludes the paper and gives direction for future work.

\section{Related Work}

\subsection{International Treatment Programs for Autism}

Communication happens when one person sends a message to another either verbally or non-verbally. With Autistic children, communication is difficult because they are visual thinkers. For this reason, pictures are the first language they would be interested in and words are their second language. Therefore, most of international treatment program use pictures to help these children in communication. These programs have the same aim of children rehabilitating but using different approaches with a mutual goal of helping in children treatment via enhancing their communication skills. 
There are several autism centers use international treatment programs and they may combine them according to a center's strategy. Most well known programs are summarized in the following.

\section{ABA (Applied Behavior Analysis)}

Applied Behavior Analysis (ABA) is the science of human behavior. It involves applying behavioral principles and techniques to improve socially significant behavior. ABA therapy is two-fold: interventions are used to increase behaviors that are not occurring at an appropriate rate (i.e. the individual has a skill deficit) or interventions are used to decrease behavior that is occurring too frequently (i.e. problem behavior.) [3] .

The goal is to determine what happens to trigger a behavior, and what happens after that behavior that seems to reinforce the behavior. The idea is to remove these triggers and reinforce from the child's environment. New reinforcement is then used to teach the child a different behavior in response to the same trigger. [4]

There is no cut-off age for ABA therapy as it helps individuals of all ages, including older adults. However, for the most effective therapy, early intervention is the key. Specialists recommend children in need of ABA therapy begin services before the age of 5 to have the best possible outcome. [3]

2. TEACCH (Treatment and Education of Autistic and related Communication handicapped Children)

TEACCH is a complete program of services for autistic people which makes use of various associated techniques depending upon the individual person's needs and emerging capabilities.

The main goal of TEACCH is to help autistic children grow up to their maximum ability by adult age. Advocates of TEACCH state that it aims for a 'whole life' approach in supporting children, adolescents, and adults with an Autistic Spectrum Disorder such as Autism or Asperger syndrome, through the help of visual information, structure and predictability. There is an emphasis on continuance care so where services are available, it is possible for an individual with an Autistic Spectrum Disorder to be supported from two years of age into adulthood. [5]

\section{PECS (Picture Exchange Communication System)}

PECS is a form of augmentative and alternative communication (AAC) that uses pictures instead of words to help children communicate. PECS was designed especially for children with autism who have delays in speech development. [6]

The main goal of PECS is to help autistic children begin to understand the usefulness of communication, then begin to use natural speech. The effective age of the youngest child was three years, and the oldest was twelve years [7]. It can be used in schools, homes and therapy setting .[6] 
PECS may also help improving social interactions in autistic children. Because the child is in charge of approaching the communication partner, the child learns how to make the first move. For autistic children, approaching another person socially can be difficult. However, in this case, the child is not expected to speak, so the initial approach may be less intimidating.[8]

\section{BHS (Boston Higashi School)}

Boston Higashi School is a unique educational philosophy, developed by the late Dr. Kiyo Kitahara and Mr. Katsuhei Kitahara who were the founders of both the Musashino Higashi Gakuen School in Tokyo, Japan and the Boston Higashi School, in Randolph, MA. [9]

This school incorporates a broad and balanced curriculum including academics, art, music, physical education, computer technology and social education. Students take on challenges, learn to overcome obstacles and gain confidence from their own success. [9]

Boston Higashi School help children and young adults with Autism Spectrum Disorder to learn to reach their full potential through the application of the methodology of Daily Life Therapy, this process allows students to develop a love for learning so they may fully enjoy their family, community, and all that life has to offer. As students grows and learns, their personality and individual character matures allowing them to benefit from and, most importantly, contribute to society as adults. Its students are from 3 years old through 22 years old who do not suffer from severe mental retardation, uncontrolled seizures or physical disabilities. [9]

\subsection{Software Solutions for Autism}

Games for autistic children can provide many educational benefits. There are variety of single-player and multiple-player games that can improve important developmental and behavioral skills, for example

\section{MouseTrial's Autism Software}

MouseTrial's autism software is a collection of fun-filled exercises and games design for Autistic children. It is based on ABA treatment to develop the vocabulary and Communication in children with autism.[10]

The main goal of the MouseTrial is to help kids with autism on [11]

- Concentration: the ability to focus on an exercise for increasingly long periods.

- Cooperation willingness: to take part in activities when asked to.

- Vocabulary Acquisition and retention of new words and their meanings.

- Literacy Recognition of written words and letters (by switching pictures).

MouseTrial is used by children covering a very wide range of ages from toddlers to teenagers. You can adjust the level of difficulty to make sure that the player is 
successful most of the time while still making progress and encountering new challenges. [12]

\section{ZAC Browser (Zone for Autistic Children)}

It is the first browser for Autistic children that include games, stories , music and videos. It was designed to offer a pleasant, rewarding children sing, play and discover the best that the Internet has to offer with only a few clicks of the mouse. [13]

The main goal of ZAC is the zone that will permit the child to interact directly with a lot of games and activities (focused on many interests) that cater specifically to children who display the characteristics of autism spectrum disorders, like impairments in social interaction, impairments in communication, restricted interests and repetitive behavior. ZAC has been an effective tool for children and high functioning autism. . [13]

\subsection{Related Work Analysis}

In the following table, we compare the common treatment programs and software against the criteria that we specified for Autistic enhancement program .

Table 1. Evaluation of treatments and software programs

\begin{tabular}{|c|c|c|c|c|c|c|}
\hline \multirow[t]{2}{*}{ Criteria } & \multicolumn{4}{|c|}{ Treatment Programs } & \multicolumn{2}{|c|}{$\begin{array}{l}\text { Software Pro- } \\
\text { grams }\end{array}$} \\
\hline & TEACCH & PECS & $\mathrm{ABA}$ & Higashi & $\begin{array}{c}\text { Mouse } \\
\text { Trial }\end{array}$ & $\begin{array}{r}\text { ZAC } \\
\text { browser }\end{array}$ \\
\hline $\begin{array}{l}\text { 1) Communication skills : } \\
\text { 1-1 Follow commands }\end{array}$ & $\sqrt{ }$ & $\sqrt{ }$ & $\sqrt{ }$ & $\sqrt{ }$ & $\sqrt{ }$ & \\
\hline $\begin{array}{l}\text { 1-2 Identify Vocabu- } \\
\text { lary }\end{array}$ & $\sqrt{ }$ & $\sqrt{ }$ & $\sqrt{ }$ & $\sqrt{ }$ & $\sqrt{ }$ & $\sqrt{ }$ \\
\hline $\begin{array}{l}\text { 1-3 Link words to their } \\
\text { meaning }\end{array}$ & $\sqrt{ }$ & $\sqrt{ }$ & $\sqrt{ }$ & $\sqrt{ }$ & $\sqrt{ }$ & $\sqrt{ }$ \\
\hline $\begin{array}{l}\text { 2) Sociability : } \\
\text { 2-1 Eye contact }\end{array}$ & $\sqrt{ }$ & $\sqrt{ }$ & $\sqrt{ }$ & $\sqrt{ }$ & $\sqrt{ }$ & $\sqrt{ }$ \\
\hline $\begin{array}{l}\text { 3) Awareness of environ- } \\
\text { ment }\end{array}$ & $\sqrt{ }$ & $\sqrt{ }$ & $\sqrt{ }$ & $\sqrt{ }$ & $\sqrt{ }$ & $\sqrt{ }$ \\
\hline $\begin{array}{l}\text { 4) Structure teaching } \\
\text { 4-1 Look at pictures }\end{array}$ & $\sqrt{ }$ & $\sqrt{ }$ & $\sqrt{ }$ & $\sqrt{ }$ & $\sqrt{ }$ & $\sqrt{ }$ \\
\hline $\begin{array}{l}\text { 4-2 Define the main } \\
\text { part } s \text { of the house }\end{array}$ & $\sqrt{ }$ & $\sqrt{ }$ & & $\sqrt{ }$ & $\sqrt{ }$ & \\
\hline 4-3 Religious habits & & & & & & \\
\hline 4-4 Daily habits & $\sqrt{ }$ & $\sqrt{ }$ & $\sqrt{ }$ & $\sqrt{ }$ & $\sqrt{ }$ & \\
\hline $\begin{array}{l}\text { 4-5 Awareness of dan- } \\
\text { ger }\end{array}$ & & & & $\sqrt{ }$ & & \\
\hline
\end{tabular}


Table 1. (Continued)

\begin{tabular}{|c|l|l|l|l|l|l|}
\hline $\begin{array}{c}\text { 5) Software features : } \\
\text { 5-1 Interaction }\end{array}$ & & & & & $\sqrt{ }$ & $\sqrt{ }$ \\
\hline $5-2$ User friendly & & & & & $\sqrt{ }$ & $\sqrt{ }$ \\
\hline $5-3$ Freely available & & & & & & $\sqrt{ }$ \\
\hline $5-4$ Easy to download & & & & & $\sqrt{ }$ & $\sqrt{ }$ \\
\hline 5-5 Using 3D modals & & & & & & $\sqrt{ }$ \\
\hline
\end{tabular}

As a result of the analysis presented above, we have determined the requirements of our virtual reality software by incorporating some features found in the treatment programs and others that are not available in the related software such as building up their religious habits, awareness of danger and the manners they need inside the house, which will improve their overall behavior.

\section{Requirements Specification}

We have determined the program's requirements based on the results concluded from the literature review of the International treatment programs, software and the collected data from the interview the specialists and questionnaire.

The project requirements are categorized in two groups: functional and non-functional.

\subsection{Functional Requirements}

This subsection represents the activities and behaviors that the program must provide for autistic children.

- Provide a welcome page that will contain description of the game.

- The house contains four rooms : bedroom, kitchen, living room and bathroom

- In the kitchen, the child will learn:

$\circ$ Decencies of eating.

- Identifying the name of fruits, vegetables and kitchen tools.

- Asking the child about the name of food and tools to make sure of his understanding.

- In bedroom, the child will learn:

- Defining how to pray and asking the child about it.

○ Teaching the child the sleeping decencies.

- In bathroom, the child will learn:

- Identifying the steps of ablution and asking the child about it.

- Identifying the steps of brushing teeth and asking the child about it. 
- Identifying the tools of bathroom.

- Identifying the bathroom decencies.

- In living room the child will learn :

- Reading book to recognize the animals and colors.

- Playing puzzle to improve his concerning ability.

\subsection{Non Functional Requirements}

This subsection represents the features, characteristics and constraints that provide a satisfactory program for autistic children.

- Colours and sounds must be appropriate.

- The graphics and animations in virtual reality will be simple, does not contain a lot of shapes that may disturb the child.

- Repeat the questions to child if he chooses wrong answers.

\section{Software Architecture}

The environment is a typical house consists of living room, kitchen, bedroom and bathroom . The scenario will be as follows:

The first interface will contain three buttons (Start -How to play - Exit), start button to start the game, how to play button contains general instruction as a guidelines to use the game and exit button to exit from the game. If the child selects start button, the animated character called Amjed, who will guide the child with autism through the virtual reality, will introduce himself and name of te rooms to the child. Then a list of rooms will appear to the child to select which room he wants to play in .

- The child selecting the living room :

In the living room the child can read books of animals, colors and Amjed will utter the name of each animals, color to clarify and facilitate the understanding. Alternatively, the child can play a set of puzzles to increase his mental skills. Also he can go back to the list of rooms by selecting exit button .

- The child selecting the kitchen :

Amjed will teach the child eating decencies and introduce him to the name of kitchen tools and some fruits. Then, automatically a set of match games will appear containing fruits, vegetables and kitchen tools. The child must click on the appropriate picture depending on the matching words. If he select a wrong picture, three buttons will appear ( help - try again - exit ). Help button will show the correct answer, try button will return the child back to the last correct answer then he can complete the game, while exit button will exit from the game to the list of rooms. If the child 
answers correctly, a winning window will appear with motivating song then he will directly go to the list of rooms .

- The child selecting the bedroom :

Amjed will teach the child sleeping decencies and the steps of pray with animation and sound. After that, a pray match game will appear, in which the child must select the appropriate picture depending on the order of pray's steps. If he select a wrong picture, three buttons will appear ( help - try again - exit ). Help button will show the correct answer, try button will return the child back to the last right answer then he can complete the game, while exit button will exit from the game to the list of rooms . If the child answers correctly, a winning window will appear with motivating song then he will go directly to the list of rooms .

- The child select the bathroom :

There will be four buttons in the bathroom, ( let's learn ablution - let's learn brushing teeth - let's learn bathroom tools - exit ). If the child selects "let's learn ablution ", Amjed will teach him the ablution steps then ablution match game will appear in which the child must select appropriate picture depending on the order of ablution's steps. If the child selects " let's learn brushing teeth ", Amjed will teach the child the brushing teeth steps then brushing teeth match game will appear, in which the child selects appropriate picture depending on the order of brushing teeth's steps. If the child selects "let's learn bathroom tools ", Amjed will utter the name of bathrooms tools for the child to recognize. For each matching game, if the child selects a wrong picture, three buttons will appear ( help - try again - exit ). Help button will show the correct answer, try button will return the child back to the last correct answer then he can complete the game, while exit button will exit from the game to the bathroom . If his answer is correct, then a winning window will appear with motivate song. When he finishes any game and returns back to the bathroom, he can select exit button to return back to the list of rooms .

\section{Implementation}

The tools that have been used to implement the virtual reality are Blender, Make human 1.0 alpha 5.1, Python, Adobe Audition 3.0, Format factory, Adobe Photoshop and Microsoft Office Visio 2007. The implementation process consists of four phases:

1. Modeling and Texturing.

2. Animation.

3. Game logics.

4. Direction.

We started building the house as plans, which was developed to form as a complete house structure, and then we built and textured each room individually. Afterwards, we built the character, named "Amjad" using Make Human software and we added 
some modification on it such as clothes, shoes and hair using Blender. This was followed by defining the game logics for each room including animation of the character and the activities. Finally, in direction phase, we modified the size of the camera and equality in all scenes so that the required parts are visible. These phases are shown in figures 1-3 for the living room as an example. The software was produced in executable format (.exe), so that any user can easily download and run it.

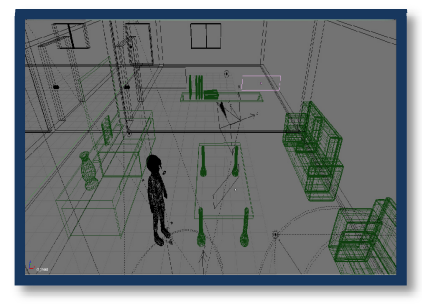

Fig. 1. Modeling phase of living room

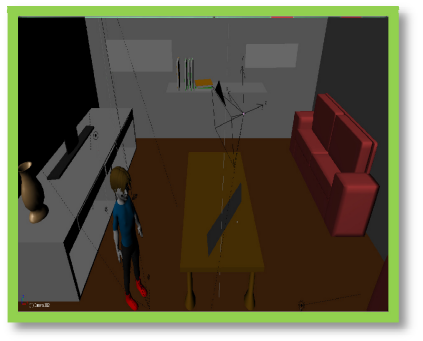

Fig. 2. Texture phase of living room

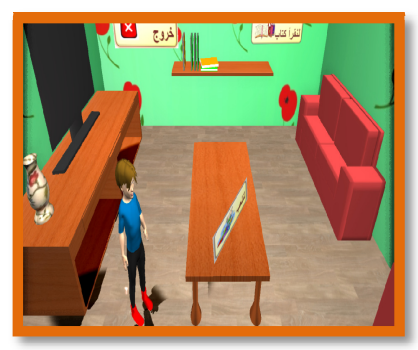

Fig. 3. Complete living room

\section{Results}

We have tested the project on a sample of 10 autistic children in the specified age group. The test showed that the software was easy for them to use. The use of colors and sounds was suitable to their condition. The scores of the games following each 
activity showed that the children have gained benefit and that they learnt the presented behavior and skills successfully.

The project was presented to the specialists from Dubai Autism Center and Jeddah Autism Center for evaluation. They found that he buttons in home page are clear. They also found that the colors and furniture are appropriate and non-dispersive for the autistic children. The songs were found to be non-disturbing for most children. At the end, they concluded that the developed software is appropriate for autistic children as it covers several domains, i.e. Cognitive, Social, Self-care. The developed software has the advantage of implementing visual stimuli which is a source of strength for autistic children.

\section{Conclusion}

Based on the recommendations of specialists and the results of tests we found that the idea of simulating the real home using the virtual reality helps the autistic children to get the acquired skills and learnt better to get other skills. Autistic child is like any normal child possesses the effective skills but need a special software to discover and develop those skills. The future work will be extending the software to include environment outside the house, i.e. streets, schools, supermarket, etc.

\section{References}

1. My child without limits, http: / /www. mychildwithoutlimits.org/?page=autism

2. Wikipedia, http://en.wikipedia.org/wiki/Epidemiology_of_autism

3. Autism Learning Felt, http://www.autismlearningfelt.com/2010/04/ providing-aba-therapy-for-your-child.html

4. Healing Thresholds, http://autism.healingthresholds.com/therapy/ applied-behavior-analysis-aba

5. Bright Tots, http://www.brighttots.com/TEACCH_Method_autism

6. Healing Thresholds, http://autism.healingthresholds.com/therapy/ picture-exchange-communication-system-pecs

7. National Professional Development Center on Autism S spectrum Disorders, http://autismpdc.fpg.unc.edu/sites /autismpdc.fpg.unc.edu/ files/PictureExchangeCommunication_Brief_0.pdf

8. Pedia Staff, http://www.pediastaff.com/resources-picture-exchange -communication-system-featured-october-13-2011

9. Boston Higashi School, http: / /www.bostonhigashi.org/about.php?id=7notused

10. Mouse Trial Autism Software, http://www.mousetrial.com/index.html

11. Mouse Trial Autism Software, http://www.mousetrial.com/home_benefits.html

12. Mouse Trial Autism Software, http://www.mousetrial.com/home_suitable.html

13. PC Win, http://pcwin.com/Home_E_Education/Kids Parenting/Zac _Browser/screen.html 